spondingly high. Round the upper portion of this pillar is a strong lattice work structure, capable of rotation round the pillar, and to this is fixed the vertical telescope with a second mirror and the objective at its upper end, the lower end carrying the large spectroscope, the collimator of which is vertical. For different declinations of the object under investigation the vertical telescope can be moved round in azimuth. In the communication in question Dr. Schlesinger describes all the chief portions of the instruments in detail, and numerous reproductions accompany the text. The latter part of the paper contains an investigation on the rotation of the sun by spectroscopic means made with the instrument described briefly above. Reference should be made to the paper itself for details, but the interesting table, showing the formulæ derived for the solar rotation by the spectroscopic method, may be here reproduced:-

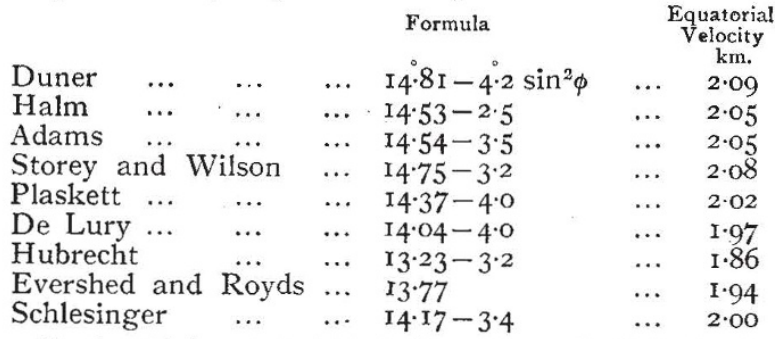

It should be stated that Duner's and Halm's observations were visual, and that Hubrecht found a difference of $0.8^{\circ}$ between the coefficients of $\sin ^{2} \phi$ for the two solar hemispheres and the value given above is the mean. Dr. Schlesinger is strongly of the opinion that the causes of the diversity of the results are due to systematic errors at the telescope and at the measuring machine.

\section{FLUCTUATIONS IN THE YIELD OF SEA FISHERIES. 1}

THERE can be little doubt that this report by Dr. Hjort will mark an epoch in the history of scientific fishery investigations. If the arguments upon which its conclusions are based successfully withstand the test of criticism, there has been established a method of predicting the probable future course from year to year of some of our most important fisheries, which should be of the utmost value both to those engaged practically in the fishing industry and to those responsible for fishery administration.

The report is the result of many years of observation, and although the lines upon which the work has proceeded, and the character of the results which were expected, have been described by Dr. Hjort and his fellow-workers from time to time, this is the first report in which the whole matter has been brought forward in a comprehensive way, and the first time that all the data upon which the conclusions are based have been available. It is now possible to form a judgment as to the value of the work already done and as to the promise which it holds out of still more useful results in the future.

It is one of the most characteristic features of the great sea fisheries that they are subject to remarkable fluctuations from time to time. Sometimes these fluctuations are seasonal, sometimes annual, but more often, perhaps, we have a series of years of successful fishery, followed by another series of comparatively

1 Fluctuations in the great fisheries of Northern Europe viewed in the light of biological research. By Johan Hjort. Con. perm. internat. Explor. Mer. Rapp. et proc. verb. XX. Copenhagen, rgr4. lean years. These fluctuations are especially noticeable in the case of the fisheries for the so-called pelagic fish, such as the herring, mackerel, pilchard, and anchovy, and, to a less-marked degree, in the case of the cod and haddock. Dr. Hjort's principal results refer to the herring, but a considerable amount of attention has also been given by him and his colleagues to the cod and haddock.

The case of the herring is the most conclusive. The main evidence has been obtained by the determination of the age of the fish from the markings on the scale. As in the case of many other fishes, there is little or no growth of the fish during the winter, and the difference in growth between winter and summer is clearly marked on the scale of the fish, the period of small winter growth being represented by a dark mark or ring. By counting the number of such rings the age of the fish can be determined, so that the year in which it was born becomes known. In a sample of the fish taken at any particular time it is therefore possible to determine ir what proportions the different year classes are represented.

This method of age analysis has now been applied to Norwegian herring for a series of years with somewhat remarkable results. It has been found during the period 1907 to 1914 that fish of the year class I904, that is to say, fish born in the year I904, have occupied a very prominent position throughout, at first forming a large proportion of the shoals of smaller herring ("fat herring" as they are called in Norway, fish from $19-26 \mathrm{~cm}$., still quite immature) and in later years being equally prominent amongst the larger fish ("large herring," fish from $27-32 \mathrm{~cm}$., and "spring herring," the actually spawning fish). The following table shows the percentage of fish of the I904 year class in the samples examined each year from 1907 to 1913 :- -

Per cent. 1904 in 190719081909 I9IO I9II I9I2 1913 $\begin{array}{lllllllll}\text { Among fat herring } \ldots & 51.3 & 37.8 & 16.9 & 4.5 & 0 & 0 & 0\end{array}$ $\begin{array}{lrrrrrrrr}\text { Among large herring } & 7.7 & 51 \cdot 6 & 48.8 & 59 \cdot 6 & 46.0 & 52.5 & 58.6\end{array}$ $\begin{array}{llllllll}\text { Among spring herring } \quad I \cdot 0 & 34 \cdot 8 & 43.7 & 77 \cdot 3 & 70 \cdot 0 & 64.3 & 64.7\end{array}$

The I904 fish, therefore, formed more than 50 per cent. of the immature "fat herring" in $\mathrm{r}_{90} \mathrm{O}_{7}$, and occurred amongst this class of fish in diminishing proportion until 19lo. Amongst the "large herring," 51.6 per cent. were 1904-spawned fish already in 1908, and fish of the same year class occurred in large proportions each year until 1913 , when there were still $5^{8.6}$ per cent. Turning to the "spring herring"-the large spawning fish-the I904 group was represented each year by a larger percentage, until in I9Io it constituted 77.3 per cent. of all the fish. Since that time the percentage has only slightly fallen off, being still $64 \%$ per cent. in 1913. In the last chapter of the report the figures for 1914 are given, the percentages of the different year groups amongst the spring fish being as follows (p. 2I9) :-

Spring Fish, I9I4. Total number of Herrings

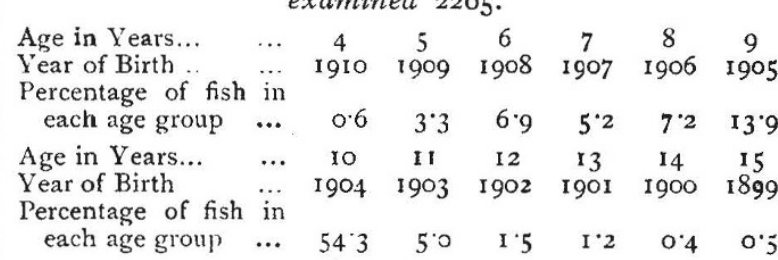

In the year I9I4, therefore, we still have, in the samples examined, 54.3 per cent. of the fish derived from the spawning of the year I904. It should be added that the 2,205 fish are the combined total of eight samples taken at different points on the Nor- 
wegian coast, and that each individual sample shows the same predominance of the 1904 class. It is also equally well shown in seven samples of "large herring" taken during the winter of $19 \mathrm{I}^{\mathrm{I}} 3 \mathrm{-I} 4$.

The next step in Dr. Hjort's argument is based on a study of the fishery statistics showing the fluctuations in the total yield of herrings of the different kinds. $\mathrm{He}$ is able to show that a marked increase of the yield occurred in those years in which the rgo4 class became prominent.

The report then goes on to a study of the cod and haddock, and evidence is produced of a similar series of phenomena in the case of these fish. Again, the 1904 year class is predominant for a number of years, and its abundance gives rise to a successful fishery.

Summing up the whole matter, Dr. Hjort claims that the renewal of the stock of fish does not take place, as in any human population, by means of a more or less constant annual increment in the form of new individuals, but that, in the case of the species investigated, it is of a highly irregular character. "At certains intervals, year classes arise which far exceed the average in point of numbers, and during their lifetime, this numerical superiority affects the general character of the stock, both as regards quantity and quality, thus again exerting a decisive influence upon the yield of the fisheries in both respects." These rich year classes make their presence felt when they are still quite young, and their influence on the yield of the fisheries extends through a number of years. It should, therefore, in future, by means of properly organised investigations, be possible to ascertain beforehand the probable general course of the fisheries over a series of years. Such predictions will, of course, be liable to be upset by special circumstances, both of a general and of a local character. Nevertheless, there is now good reason to hope that indications of great practical value may be given, if the methods of investigation advocated by Dr. Hjort are continued upon an adequate scale. E. J. A.

\section{STUDIES OF TROPICAL DISEASES. ${ }^{1}$}

$T H I S$ report consists of the report of the committee (2 pp.) and six appendices, the first of which deals with anti-malarial measures in the Crown Colonies and protectorates, etc., the remainder with reports of the work done in various laboratories. To consider, first, Appendix I. The data in this appendix are mainly statistical. They seem to us to be deficient in two ways. (I) The figures are not scrupulously accurate, or at least differ from other official figures. (2) Information is lacking which seems to be essential to an appreciation of the meaning of the figures. Of want of accuracy, the following are examples. On p. II in the Mauritius report the number of deaths ascribed to fever (malaria included) is given as 4498 , whereas in the annual report for Mauritius the deaths due to malaria only are given as 46rg. Again, under the heading, "Government Hospitals," we find malarial fever: admissions $232 \mathrm{I}$, deaths 30 , whereas in the annual report for Mauritius we find 3063 cases of malaria, and 43 deaths. The discrepancy here may be due to the fact that in the latter case other than hospital cases are recorded, but if this is so, at any rate they find no place among the data in this report.

Again, comparing the figures given in this report and in the annual medical report for the Straits Settlements, we find the figures for malarial admissions to be 9172 and 9474 respectively, a difference of 302 . In the corresponding reports for Nyasaland we find the population given as $\mathrm{I}, 000,659$ and $\mathrm{I}, 00 \mathrm{r}, 895$ respec-

1 Report of the Advisory Committee for the Tropical Diseases Research Fund for the Year r 913 .

NO. 2339, VOL. 93] tively. In the Southern Nigerian report (p. 35) we find the following puzzling figures under malarial fever, viz. :-Admissions, 6; deaths, Io; admissions, 7 ; deaths, 5; admissions, I; deaths, Io. And again, under "Government Hospitals," we find the admissions given as 9687 , and two lines further down as 1365 ! Under "Blackwater Fever" four deaths are recorded, but no admissions are given, and it is only by referring to the annual medical report that we find that the number of cases in the colony was twentythree. Not to pursue the subject further, we would only add that in our opinion the heading, "Deaths Ascribed to Fever," is ambiguous, as apparently some medical officers have found it to be, for some change the heading to "Malaria Fever," others sav "malaria included," whereas others again subdivide it into malaria, typhoid, and non-specified fevers. We think this heading should be changed to "Diseases During the Year," and divided into various sub-headings, e.g. malarial fever, blackwater fever, etc., with the addition, if necessary, of unclassified fevers, and in each instance where possible cases as well as deaths recorded, as is done under heading 6 "Government Hospitals."

The second criticism we have to make is that information is lacking which is necessary to give the figures their full value. While dreading to suggest any addition to the really burdensome labours of those who have to compile these reports, yet we cannot help feeling that a mere record of population and malarial deaths tells us less than we ought to know. In our opinion, for these figures to be really of value we should know, besides the total population, that of each race and the deaths in each race. For instance, we are given, on p. I4, the European, Chinese, "other races," and Malay population of the Straits Settlements, but while we are told that the total births are more than 20,000 , we are given no idea as to what races were responsible, and similarly we cannot tell among what populations the malarial deaths occurred. We have dwelt on these points because it seems to us that sooner or later the question of the compilation of the figures in reports of this kind and in the annual medical reports must be seriously considered. It is scarcely an exaggeration, we think, to say that at present no two annual medical reports are based on exactly the same plan, and we actually find that the official year is not identical in all. One point will not be disputed, viz., that absolute accuracy is necessary, and this is by no means an easy matter to attain, as everybody knows who has had to make up tables of figures. Whether these matters should not be in the hands of trained statistical officers, instead of being thrown on the shoulders of already overworked medical officers is a matter for consideration.

It is impossible to give shortly an adequate notice of the various researches recorded in appendices ii.-vi. as the subjects differ widely. It is evident that much valuable research is being done and interesting results got, but it occurs to us whether practical results-and we think we may assume that this is the main object of most of these researches-could not be got more quickly if the forces now scattered in various directions were to some extent concentrated on certain problems. For instance, we consider that each of the reports on the use of salvarsan in yaws (three in number) is more valuable than it would have been if it had stood alone. On ankylostomiasis we have only one report. It would be a gain to check the results recorded in it by experience elsewhere. So while not wishing to limit in any way a man's predilection, we think that coordination would be of advantage. The report is priced at $2 s$. $4 d$., but we hope that every medical officer receives a copy gratis. J. W. W. S. 